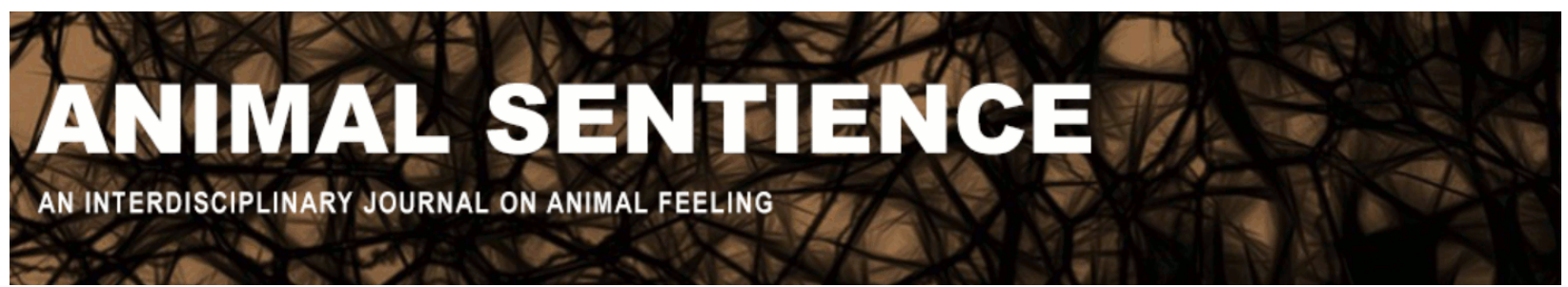

Key, Brian (2016) Falsifying the null hypothesis that "fish do not feel pain". Animal Sentience 3(39)

DOI: $10.51291 / 2377-7478.1070$

Date of submission: 2015-12-01

Date of acceptance: 2015-12-14 (c) 


\title{
Falsifying the null hypothesis that "fish do not feel pain"
}

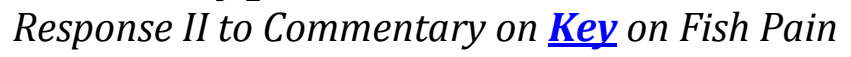

\author{
Brian Key \\ School of Biomedical Sciences \\ The University of Queensland
}

\begin{abstract}
The reader of Animal Sentience may surmise that because the weight of the commentaries on my target article, "Why fish do not feel pain," is leaning towards not supporting my argument, it follows that the premise "fish do not feel pain" is incorrect. However, science does not prevail by popular opinion. History is plagued with numerous (and often widely accepted) examples of biological phenomena being explained by mysterious forces. In the absence of a mechanistic understanding, the many different guises of vitalism (the principle that life involves a vital energy) are often invoked to explain the unknown. Spurious assumptions tend to exist when there is ignorance and misunderstanding of mechanisms. The most effective way to argue against contrived explanations is to discover fundamental causal mechanisms. Likewise, the best way to falsify the null hypothesis that "fish do not feel pain" is to investigate the underlying neural mechanisms generating pain.
\end{abstract}

\footnotetext{
Brian Key brian.key@uq.edu.au is Head of the Brain Growth and Regeneration Lab at University of Queensland. He is dedicated to understanding the principles of stem cell biology, differentiation, axon guidance, plasticity, regeneration and development of the brain. http://www.uq.edu.au/sbms/staff/brian-key

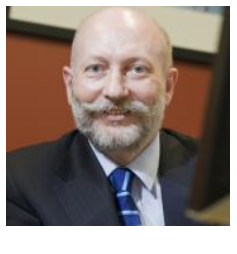

As progress is made in understanding the neurobiology of pain, there will be no logical reason to bestow pain on animals (or plants; Baluška) that lack the neural circuitry that underpins the neural processing and computations necessary for pain. There will also be no need to invoke subjective arguments relying either on benefits of doubt, or moralistic

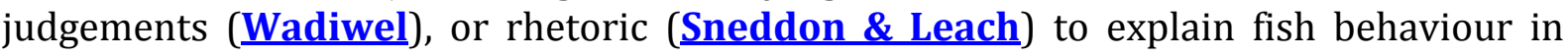
response to noxious stimuli. Dismissing the argument that structure determines function by simplifying it to the level of saying that any animal without a cortex can't feel pain or rephrasing it to suggest that only the "complete human system for pain can generate the experience of pain" (Elwood; Merker; Segner; Sneddon \& Leach) does not cancel the need to decipher the casual mechanisms of pain. Furthermore, it is not good enough to suggest that because conscious awareness is still not completely understood in humans ( $\underline{\text { Stevens}}$ ), we can't begin to propose reasonable inferences with regard to fish.

\section{Confusing terminology}

It is important in this argument not to confuse terminology. Stevens raises the issue of terminology and how it can interfere with progress in the field. Segner states that "the 
response to pain involves a non-conscious, reflexive action and a conscious perception." The use of "the response to pain" is incorrect and should be replaced with "the response to noxious stimuli can involve." This is important because such confusion can support the folk belief that pain is in the periphery. Sneddon \& Leach talk of "painful stimuli." Once again, the stimuli they refer to are "noxious." Pain refers to the conscious awareness of the stimuli and should be distinguished from the stimulus. This distinction was eloquently articulated at the turn of the $20^{\text {th }}$ century by one of the founders of contemporary neurophysiology, Charles Sherrington. Sneddon \& Leach further conflate nociception and pain (as well as stress and pain) and then surprisingly proceed to discuss "empirical evidence for pain" as being "in touch with current thinking on brain evolution." This line of reasoning easily leads to anthropomorphic conclusions, such as that fish engage in "deception."

\section{Alternative anatomies have been tried and found wanting}

I have argued very explicitly that signal amplification and global integration underlie the conscious processing associated with pain (Key 2015a, Key 2015b; Key 2016a, Key 2016b). The principal neural circuitry responsible for these phenomena was then identified in humans, rodents and probably birds, and subsequently demonstrated to be lacking in fish. Others have adopted similar approaches and reached the same conclusions ( $\underline{\text { Rose)}}$ ). It is not helpful to simply reject the existing neuroscience and instead resort to mysterious processes occurring somewhere else in the brain (Gagliano; Godfrey-Smith; Goncalves-de-Freitas; Sneddon \& Leach) without a genuine attempt to propose how these regions are mechanistically responsible.

Although Panksepp and Merker have suggested that the brainstem and other subcortical regions support emotions, they use reflexive motor behaviours inappropriately as measures of hypothetical feelings. There is no doubt that these regions participate in motor output, but the feeling is associated with specialised neural circuitry as reported (Key 2016a). Merker elevates the midbrain tectum to a fundamental role in fish pain even though tectal ablation does not perturb responses to noxious stimuli, and this region lacks the necessary neural architecture (Key 2016a). There is no evidence that the tectum in primates contributes directly to conscious awareness (Lovejoy and Krauzlis, 2010), but it is certainly involved in bottom-up attentional mechanisms (Clark et al., 2015).

Shriver argues that the lesion data on the role of the insula in human pain is not entirely clear; he then proposes that this undermines my interpretation. My discussion of this matter in the target article is unfortunately overlooked by Shriver, who mistakenly suggests that I did not discuss the work of Starr et al. (2009). As I explicitly articulated, the argument is not about a single brain region; rather, it encompasses the broader neural architecture and circuitry that allow signal amplification and global integration.

Burghardt suggests that pain could arise in the cerebellum because it is disproportionately large in some species. This size hypothesis lacks any credibility and any level of explanatory power particularly when one realizes that the granule cell population in the human cerebellum is about four times the total number of all neurons in the cerebral cortex (Anderson et al., 1992). Segner suggests that the structurefunction approach is somehow flawed because recent evidence that human "babies, at 
least from week 35-37 onward, are able to perceive pain" conflicts with prior literature indicating that immature human nervous systems may not be capable of feeling pain. I won't go into the details of this literature here, but Segner seems to misunderstand that science is always probing and refining hypotheses. Nonetheless, these early human infant studies appear very promising, and one hopes they will lead to a better understanding of the neurophysiology and neural circuits underlying pain.

To argue that because vision is possible in animals with brains different from those of humans, it follows that animals with different brains must be able to feel pain (Elwood) is unfortunately to misunderstand the problem. It is important not to confuse the generic term vision with the qualia or phenomenal conscious experience of vision (what it feels like to see "red"). Confusing these terms quickly leads to the idea that facial recognition software can experience visual information. My argument clearly dismisses such a possibility.

\section{Searching for conscious behaviours has been unrewarding}

Trawling through the literature for possible examples of behaviour that could be

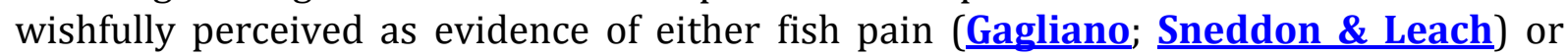
crab pain (Godfrey-Smith) or felt emotions (Merker; Panksepp) - or resorting to just-so stories to the effect that fish display any behaviour that "mammalian cortical pain regions make possible" (Shriver) - does not contribute to understanding mechanisms. Likewise, hoping for the development of a fish scale for somatic responses to noxious stimuli (van Rysewyk) is not helpful.

Shriver suggests that conditioned place preference is "one of the best measures of pain behaviour in nonhuman animal models" but then correctly acknowledges that there is no a priori reason why this requires conscious experience. Consequently, he then suggests that trace conditioning may be a better measure since it appears to require conscious awareness. The idea that trace conditioning requires conscious awareness has been hotly debated since Clark and Squire (1998) correlated conscious awareness of the contingency between conditioned and unconditioned stimuli with successful trace conditioning. More recently, it has become apparent that trace conditioning can be performed without the need for either conscious awareness of the unconditioned stimulus or contingent awareness between stimuli (Eichenbaum, 1999; Perruchet et al., 2015; Price, 2015). Consequently, trace conditioning cannot be considered a good measure of conscious awareness in fish as proposed by $\underline{\text { Shriver. }}$

\section{Gene expression is not behaviour}

It needs to be pointed out that evidence of an animal expressing a gene in one species is not evidence that it is indicative of a particular behaviour in any other species. Gene expression needs to be placed in the broader context of the micro-environment in which it is expressed (i.e., other genes, cells, tissues and organs). Sneddon \& Leach suggest that the expression of opioid receptors is evidence for fish feeling pain. This logic is like assuming that any species expressing ion channels must be capable of metacognition. The complex neurobiology associated with morphine function in the nervous system needs to be appreciated. Unfortunately, Sneddon \& Leach's misunderstandings of a number of basic concepts in their commentary results in erroneous reasoning. 


\section{Pain by another name}

One cannot dismiss the notion that fish do not feel pain by attempting to explain away the problem with an alternate definition of fish pain. Disguising the problem with terms such as "undifferentiated consciousness" (Burghardt) or "raw experience" does not dismiss the need to understand casual mechanisms. Derbyshire points out clearly that the idea of "raw experience" is not a proxy for pain. However, if such terms are introduced, then they too demand mechanistic explanations.

\section{Falsification of the null hypothesis}

There is no need to resort to hypothetical explanations about the evolutionary benefits of pain to fish survival - or to just-so stories about complex fish behaviours - in the attempt to falsify the null hypothesis that "fish do not feel pain." Deciphering the neural mechanisms responsible for pain will reveal decisively whether fish are capable of feeling noxious stimuli as pain. The experimental approaches are now well established, and evidence to date indicates that the null hypothesis has not been rejected.

\section{References}

Anderson, B.B., Korbo, L. and Pakkenberg, B. (1992) A quantitative study of the human cerebellum with unbiased stereological techniques. J. Comp. Neurol. 326:549-560.

Baluška, F. (2016) Should fish feel pain? A plant perspective. Animal Sentience 2016.023

Burghardt, G.M. (2016) Critical anthropomorphism. Animal Sentience 2016.024

Clark, K., Squire, R.F., Merrikhi, Y. and Noudoost, B. (2015) Visual attention: linking prefrontal sources to neuronal and behavioural correlates. Progr. Neurobiol. 132:5980 .

Clark, R.E. and Squire, L.R. (1998) Classical conditioning and brain systems: The role of awareness. Science 280:77-81.

Derbyshire, S.W.G. (2016) Fish lack the brains and the psychology for pain. Animal Sentience 2016.025

Eichenbaum, H. (1999) Conscious awareness, memory and the hippocampus. Nature Neurosci. 2:775-776.

Elwood, R.W. (2016) A single strand of argument with unfounded conclusion. Animal Sentience 2016.026

Gagliano, M. (2016) What would the Babel Fish say? Animal Sentience 2016.027

Godfrey-Smith, P. (2016) Pain in parallel. Animal Sentience 2016.028 
Gonçalves-de-Freitas, E. (2016) Fish and pain welfare. Animal Sentience 2016.029

Jensen, K., Kirsch, I., Odmalm, S., Kaptchuk, T.J. and Ingvar, M. (2015) Classical conditioning of analgesic and hyperalgesic pain responses without conscious awareness. Proc. Natl. Acad. Sci. USA 112:7863-7867.

Key, B. (2015a) Fish do not feel pain and its implications for understanding phenomenal consciousness. Biol. Phil. 30:149-165.

Key, B. (2015b) Why fish (likely) don't feel pain. Scientia Salon Feb $5^{\text {th }}$ https://scientiasalon.wordpress.com

Key, B. (2016a) Why fish do not feel pain. Animal Sentience 2016.003

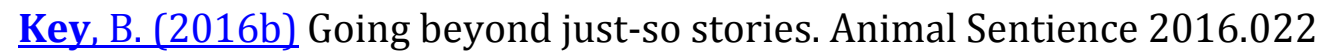

Lovejoy, L.P. and Krauzlis, R.J. (2010) Inactivation of primate superior colliculus impairs covert selection of signals for perceptual judgements. Nature Neurosci. 13:261-267.

Merker, B. (2016) Drawing the line on pain. Animal Sentience 2016.030

Panksepp. J. (2016) Brain processes for "good" and "bad" feelings: How far back in evolution? Animal Sentience 2016.031

Perruchet, P., Grégoire, L., Aerts, K. and Poulin-Charronnat, B. (2015) Dissociating conscious expectancies from automatic-link formation in an electrodermal conditioning paradigm. Psycholog. Res. In press.

Price, D.D. (2015) Unconscious and conscious mediation of analgesia and hyperalgesia. PNAS 112:7624-7625.

Rose, J.D. (2016) Pain in fish: Weighing the evidence. Animal Sentience 2016.032

Segner, H. (2016) Why babies do not feel pain, or: How structure-derived functional intepretations can go wrong. Animal Sentience 2016.033

Shriver, A. (2016) Cortex necessary for pain - not in the sense that it matters. Animal Sentience 2016.034

Sneddon, L.U. and Leach, M.C. (2016) Anthropomorphic denial of fish pain. Animal Sentience 2016.035

Starr, C.J., Sawaki, L., Wittenberg, G.F., Burdette, J.H., Oshiro, Y., Quevedo, A.S. and Coghill, R.C. (2009) Roles of the insular cortex in the modulation of pain: insights from brain lesions. J. Neurosci. 29:2684-2694.

Stevens, E. D. (2016) Why is fish "feeling" pain controversial? Animal Sentience 2016.036 
Animal Sentience 2016.039: Response II to Commentary on Key on Fish Pain

Van Rysewyk, S. (2016) Nonverbal indicators of pain. Animal Sentience 2016.037

Wadiwel, D. (2016) Fish and pain: The politics of doubt. Animal Sentience 2016.038 